Jitendra Vohra ORCID iD: 0000-0002-5676-5323

\title{
Editorial: Cardiac or T wave Memory after Radiofrequency ablation of Right ventricular outflow tract ectopics
}

\author{
Jitendra Vohra, MD \\ Cardiology Department, \\ The Royal Melbourne Hospital \\ University of Melbourne. \\ Victoria, Australia \\ Correspondence: E mail: jitu@vohra1.com \\ Disclosures: None
}

\section{Editorial: Cardiac or T wave Memory after Radiofrequency ablation of Right ventricular outflow tract ectopics.}

Introduction: The term cardiac or T wave memory describes the phenomenon of persistent $T$ wave abnormalities, for a variable length of time, even when the QRS abnormality originally responsible for the $\mathrm{T}$ wave changes has returned to normal. Table_1 lists situations where $\mathrm{T}$ wave memory is observed. The T wave changes in the above-mentioned conditions are secondary to abnormal depolarization, but they remain abnormal even after the abnormal depolarization has returned to normal. Generally, the direction or the vector of the $\mathrm{T}$ wave is the same as that of the previously abnormal QRS, hence the term Cardiac or T wave memory. These changes persist for a period of time, which varies from days to weeks, before returning to normal.

T wave memory was first reported by Campbell in 1942 (1) and T wave changes following ventricular pacing was reported by Chatterjee et al in 1969 (2). Denes et al described $\mathrm{T}$ wave memory in patients with intermittent left bundle branch block

This is the author manuscript accepted for publication and undergone full peer review but has not been through the copyediting, typesetting, pagination and proofreading process, which may lead to differences between this version and the Version of Record. Please cite this article as doi: 10.1111/jce.14007. 
in 1978 (3). Rosenbaum et al coined the term cardiac memory in a landmark paper in 1982 and investigated the mechanism of T wave memory for the first time (4).

\section{Notable features of Cardiac or T wave Memory:}

The $\mathrm{T}$ wave abnormality is longer lasting and more marked in patients who have had a longer lasting and more marked depolarization abnormality. The QRS abnormality has to be persistent for a while before the $\mathrm{T}$ wave memory will become manifest. Rosenbaum et al used the term accumulation to describe this phenomenon. They also pointed out the characteristic of conditioning, where changes occur in a shorter time when the heart is conditioned by the same perturbation. It was noted by Rosenbaum et al that at least 15 minutes of ventricular pacing was required before $T$ wave memory was noted on cessation of pacing. It is suggested that cardiac memory may be short term following ventricular pacing for a period of 15 minutes to 2 hours. This results in short term memory lasting from minutes to hours and long term, following pacing for a period of 2 to 3 weeks resulting in cardiac memory persisting for weeks to months (4) (Table 2).

\section{What causes Cardiac or $\mathbf{T}$ wave memory?}

Experiments on canine heart wedge preparations have shown increased circumferential strain and selective prolongation of action potential duration leading to amplified repolarization gradients, which is suggested as the basis for the $\mathrm{T}$ wave changes of cardiac memory (5). Myocyte stretch as a result of altered activation could lead to increased release of angiotensin 2 which regulates $\mathrm{K}$ channels, in particular $\mathrm{I}_{\mathrm{to}}$. Inward L type calcium currents may also be involved (6). Pharmacological blockade of angiotensin receptors and K channels and calcium channel block by amlodipine may prevent changes of cardiac memory. The mechanism of short and long term cardiac memory is discussed in detail in an article by Özgen and Rosen (7).

In this issue of JCE, Sakomoto et al describe T wave changes of cardiac memory following Radiofrequency (RF) ablation of frequent premature ventricular contractions (PVCs) originating from the Right Ventricular Outflow Tract (RVOT) (8). They compared 45 patients who underwent successful ablation defined as $<1 \%$ PVCs 1 month after ablation, with 10 patients who had unsuccessful ablation. They further subdivided the successful group depending on the number of ectopics. They analysed T wave changes, QT interval and QRST time integral value (a noninvasive predictor of repolarization properties) of 12 lead ECG before ablation and then 1 day, 3 days and 1 month after ablation.

In the successful group with the amplitude of the T wave and QRST time integral values of leads 2,3, aVR, aVL and aVF changed significantly after ablation and gradually normalized within 1 month. Additionally, the impact on the ECG 
changes depended on the number of pre-ablation PVCs. In patients with $>10,000$ ectopics the changes occurred in limb leads mentioned earlier as well as V2, while in those with $<10,000$ changes occurred only in limb leads. In those with $<5,000$ the only change was in the amplitude of the $\mathrm{T}$ wave in Lead 3. Significant changes were not observed in the unsuccessful group (8). These findings proved that the $\mathrm{T}$ wave changes were related to ablation of ectopics and not due to the myocardial damage related to delivery of RF energy.

The $\mathrm{T}$ wave changes described following RF ablation of RVOT ectopics are similar to those after ventricular pacing, non-sustained and sustained VT, intermittent bundle branch block and ventricular pacing. The increase in QRST time integral values occur in certain leads following ablation and return to normal after 1 month, this is also as expected. While the T wave memory after RVOT ectopics ablation has not been described previously it seems to follow the same rules as T wave memory after fascicular VT ablation, WPW ablation etc. The point the authors make that ectopics ablation related changes in the $\mathrm{T}$ waves could result in increase in $\mathrm{T}$ wave amplitude is worth noting.

Electrocardiographic QRST integral values in this study, and comparison with normal values derived from 607 normal subjects registered with the Japanese Circulation Society (Table 4 in the article), allows quantitative information regarding repolarization changes in different leads. While this has been reported after RF ablation in WPW from the same centre (9) the changes of T wave memory after PVC ablation is new.

\section{What is the clinical significance of $T$ wave memory?}

The main significance of $\mathrm{T}$ wave memory is the mistaken diagnosis of ischaemic heart disease when the exact cause of the $T$ wave changes is not recognized. There have been two reports of torsades de pointes attributed to $\mathrm{T}$ wave changes of cardiac memory. In one case which followed ablation of atrioventricular tachycardia the patient was also given sotalol for atrial fibrillation (10). In the second case there was significant QT prolongation following reversion to normal QRS in a patient with intermittent LBBB (11).

A limitation of this study, which has been mentioned by the authors, is the difficulty in quantifying the number of ectopics by Holter monitoring which can vary day by day. However, while it might make a difference between $>10000$ and $<10000$, it is unlikely to affect comparison between $>10000$ and $<5000$ group.

T wave memory after ablation of RVOT ectopics by Sakomoto et al is a worthy addition to the literature on this subject.

References:

(1) Campbell M.

This article is protected by copyright. All rights reserved. 
Inversion of T waves after long paroxysms of tachycardia. Br Heart J 1942; 4: 49-52

(2) Chatterjee K, Harris A, Davies G et al.

Electrocardiographic changes subsequent to artificial ventricular depolarization. Br Heart J 1969; 31: 770-779

(3) Denes P, Pick A, Miller R et al A characteristic precordial repolarization abnormality with intermittent left bundle-branch block.

Ann Intern Med 1978; 89; 55-57

(4) Rosenbaum M, Blanko H, Elizari M, et al

Electrotonic modulation of the $\mathrm{T}$ wave and cardiac memory.

Am J Cardiol 1982; 50: 213-222

(5) Jeyuraj D, Wilson LD, Zhaong J et al.

Mechanicoelectrical feedback as a novel mechanism of cardiac electrical remodelling.

Circulation 2007; 115:3145-3155

(6) Plotnikov AN, Yu H, Gellar JC et al

Role of L type calcium channels in pacing induced short term and long term cardiac memory in canine heart.

Circulation 2003; 107:2844-2849

(7) Özgen N and Rosen MR,

Cell to Bedside, Cardiac Memory: A work in progress.

Heart Rhythm 2009; 6: 564-571

(8) Sakomoto Y, Okamoto H, Keita M et al

$\mathrm{T}$ wave changes of cardiac memory caused by frequent premature ventricular contractions originating

from the Right Ventricular outflow tract.

J Cardiovasc Electrophysiology 2019

(9) Yanagawa T, Hirai M, Hayashi $\mathrm{H}$ et al,

QRST time integral values in 12 lead electrocardiograms before and after radiofrequency catheter ablation in patients with Wolff Parkinson White Syndrome.

J Am Coll Cardiol 1995; 25: 1584-1590

(10) Haverkamp W, Hördt M, Breithhardt G et al

Torsades de Pointes secondary to d,l sotalol after catheter ablation of incessant atrioventricular tachycardia- evidence for a significant contribution of the cardiac memory.

Clin Cardiol 1998;21:55-58

(11) Yoshinda K, Nakajima T, Kaneka Y et al

Implication of left bundle branch related cardiac memory initiation of Torsades de Poiuntes

Int J cardiol; 2016;27:757-758

Table 1- Cardiac or T wave Memory

This article is protected by copyright. All rights reserved. 
T Wave memory characterised by persistent but reversible $\mathrm{T}$ wave changes.

Abnormal repolarisation persists after depolarisation has returned to normal and is seen in:

- Post ventricular tachycardia or SVT with aberration

- Following ventricular pacing

- Intermittent LBBB

- Following period of pre-excitation (WPW), in intermittent WPW and after RF ablation of WPW

- syndrome

- Following ventricular ectopics

Table 2 - Features of Cardiac or T wave memory

- Minimum duration of abnormal ventricular activation of greater than 15 minutes

to observe cardiac memory

- Long term and Short-term memory

- More marked the depolarisation abnormality, more marked repolarisation

- Minimum duration of abnormal ventricular activation of greater than 15 minutesrequired to observe cardiac memory

- T wave changes are most marked in leads with negative QRS or delta waves

- T wave direction similar to QRS direction during abnormal depolarisation

- Accumulation: needs a certain time to become apparent, reach maximum effect and to revert

- Conditioning: Changes occur in a shorter time when the heart is conditioned by

- the same perturbation

This article is protected by copyright. All rights reserved. 


\section{University Library}

\section{- M M N E R VA A gateway to Melbourne's research publications}

Minerva Access is the Institutional Repository of The University of Melbourne

Author/s:

Vohra, J

Title:

Editorial: Cardiac or T wave memory after radiofrequency ablation of right ventricular outflow tract ectopics

Date:

2019-09-01

Citation:

Vohra, J. (2019). Editorial: Cardiac or T wave memory after radiofrequency ablation of right ventricular outflow tract ectopics. JOURNAL OF CARDIOVASCULAR ELECTROPHYSIOLOGY, 30 (9), pp.1557-1559. https://doi.org/10.1111/jce.14007.

Persistent Link:

http://hdl.handle.net/11343/286044 